\title{
Neurodevelopment in HIV Infected Children at Roosevelt's Hospital Infectious Diseases Clinic, in Guatemala
}

\author{
Andrea Palma ${ }^{1}$, Julio W. Juarez ${ }^{2}$ \\ ${ }^{1}$ General Physician Rafael Landívar University, Guatemala City, Guatemala \\ ${ }^{2} \mathrm{Head}$ of the Peadiatric Area of the Roosevelt Hospital Comprehensive HIV Unit, Guatemala City, Guatemala \\ Email: jwerner_juarez@hotmail.com
}

How to cite this paper: Palma, A. and Juarez, J.W. (2018) Neurodevelopment in HIV Infected Children at Roosevelt's Hospital Infectious Diseases Clinic, in Guatemala. World Journal of AIDS, 8, 1-10. https://doi.org/10.4236/wja.2018.81001

Received: September 13, 2017

Accepted: January 21, 2018

Published: January 24, 2018

Copyright $\odot 2018$ by authors and Scientific Research Publishing Inc. This work is licensed under the Creative Commons Attribution International License (CC BY 4.0).

http://creativecommons.org/licenses/by/4.0/

(c) (i) Open Access

\begin{abstract}
Background: The infection with HIV has been related to neurological disorders that are very frequent, since this virus crosses the blood-brain barrier and enters the CNS, thus affecting its neurological development. About 50\% $90 \%$ of infected patients, with an average age of onset from 19 months to 3 years old may present some types of neurological alteration during the course of the disease. Currently in Guatemala, there are no researches that show changes in the neurodevelopment of patients infected with HIV. Objective: To identify neurodevelopment of pediatric patients infected with the HIV, taking into consideration clinical and epidemiological characteristics. Materials and Methods: Fifty-six patients, who were under 8 years and 6 months of age, that met the inclusion criteria (confirmed diagnosis of HIV), were evaluated through neurodevelopment test (Bayley Test and McCarthy's Scale) during the months of May and June of 2016. Results: Within the neurodevelopment evaluation, it was discovered that between $36 \%$ and $54 \%$ of evaluated patients that were 3 years and 6 months to 8 years and 6 months old, presented alterations in more than one area of neurodevelopment, correlating it with studies performed in other countries with $30 \%-70 \%$ of neurological affection. Conclusions-All infected patients have alterations in more than one area of neurodevelopment. The most affected areas of neurodevelopment were the verbal, numerical and cognitive areas.
\end{abstract}

\section{Keywords}

Human Immunodeficiency Virus (HIV), Central Nervous System (CNS), Neurological Development 


\section{Introduction}

The comprehensive care unit for HIV and chronic infections of Roosevelt Hospital is located in the capital of Guatemala. Roosevelt Hospital is a reference center for the whole country. The pediatrics area of the HIV unit has operated since October 2003 and currently serves about 350 children living with HIV from 0 to 24 years of age, being one of the most important pediatrics areas in Central America. It offers the services of molecular biology, in addition to all the basic laboratories. Antiretroviral treatment is provided by the Ministry of Health. It has a multidisciplinary personnel that includes doctors specialized in the subject, a pharmacist, a nurse, a social worker, a nutritionist and a psychologist. Additionally, the hospital has all the medical subspecialties in the area of pediatrics.

Neurological development is necessary for learning and productivity, so developmental disorders have been associated with poor academic performance, behavioral problems, and social adjustment problems [1] [2].

The infection of the Human Immunodeficiency Virus (HIV) has been related to neurological disorders that are very frequent, since this virus can affect any part of the nervous system. This is because the HIV virus crosses the blood-brain barrier and enters the nervous system through the monocytes [3] [4] [5] [6]. During the first years of age, the virus shows a rapid progression, which can lead to more neurological complications during the person's growth, hence a poor development [7] [8].

Around 50\% - 90\% of infected patients, with an average age of onset from 19 months to 3 years old may present some type of neurological alteration during the disease, associated with a significant delay in neurological development [9] [10].

In studies conducted in Jamaica and Africa in pediatric patients infected with HIV, neurodevelopment was evaluated and compared to groups of non-infected patients, and they observed that between $20 \%$ - 30\% of the HIV-infected patients that were evaluated, had some types of alteration in their neurodevelopment, concluding that infected children have a poor performance in neurodevelopment areas compared to uninfected patients [11].

In Guatemala, there is significant underreporting of HIV-infected children. For 2011, 2371 cases were estimated in children of 0 - 14 years of age, representing $3.7 \%$ of the entire population with HIV, according to the National Center of Epidemiology [9]. For this year, there will be approximately 3726 new HIV-cases in children aged 0 - 14, of a total population of 87,252 in all of Guatemala, and this figure is increasing [10].

This study addresses he neurodevelopment of pediatric patients with HIV at the pediatric area of the infectious clinic of Roosevelt Hospital in order to identify the affected areas (motor, cognitive, verbal) correlating them with clinical and epidemiological characteristics such as: age, sex, CD4 count, viral load, and clinical stage [12].

\section{Materials and Methods}

Descriptive, cross-sectional, observational study. 
Population

132 children under the age of 8 years and 6 months of age, infected with HIV attending the outpatient unit, pediatric area of the infectious disease of Roosevelt Hospital.

Sample

56 children under the age of 8 years and 6 months, infected with HIV.

Sampling Plan

Convenience sampling: during the months of May to November of 2016, the outpatient unit, pediatric area of the infectious disease of Roosevelt Hospital was regularly attended, where a neurodevelopment test was performed on children under the age of 8 years and 6 months [12].

\section{Results}

For the development of the study, pediatric patients under the age of 8 years and 6 months, infected with HIV, were included. These patients were followed up on at the Pediatric area of the Infectious Diseases Unit of Roosevelt Hospital during May and November of 2016 [12].

Data was obtained from a sample of 56 pediatric patients infected with HIV. Important epidemiological characteristics of each patient were obtained (Table 1) during the evaluation of neurodevelopment.

Table 1. Epidemiological characterization of the sample, during the months of May to November of 2016, at the outpatient unit, pediatric infectiology of the Roosevelt Hospital. $\mathrm{n}=56$ children.

\begin{tabular}{ccc}
\hline Epidemiological Characteristics & \multicolumn{2}{c}{ Cases } \\
\hline Sex & Women $51(91.1 \%)$ Men $5(8.9 \%)$ \\
& 0 a $2^{\mathrm{a}}$ & $2(3.6 \%)$ \\
Age at time of evaluation & $>2 \mathrm{a} 4^{\mathrm{a}}$ & $11(19.6 \%)$ \\
& $>4 \mathrm{a} 6^{\mathrm{a}}$ & $17(28.9 \%)$ \\
& $>6 \mathrm{a} 8^{\mathrm{a}}$ & $15(26.8 \%)$ \\
& $>8^{\mathrm{a}}$ & $11(19.6 \%)$ \\
Scholarship & None & $12(21.4 \%)$ \\
& Some degree & $8(14.3 \%)$ \\
& $2^{\circ}$ grade & $12(21.4 \%)$ \\
$3^{\circ}$ grade & $5(8.9 \%)$ \\
Department & No age & $19(33.9 \%)$ \\
& Guatemala City & $20(357 \%)$ \\
& Other & $36(64.3 \%)$ \\
Person In charge & Mother & $35(62.5 \%$ \\
& Father & $4(7.1 \%)$ \\
& Family member & $5(8.9 \%)$ \\
& Shelter & $12(214 \%)$ \\
\hline
\end{tabular}

Source: Study Database [12] [13]. 


\subsection{Clinical Features}

The following results were obtained using data from each patient's medical record.

Data was tabulated from the first laboratory tests that were performed at the time of the diagnosis and the last laboratory tests at the time of the neurodevelopmental test (Graph 1).

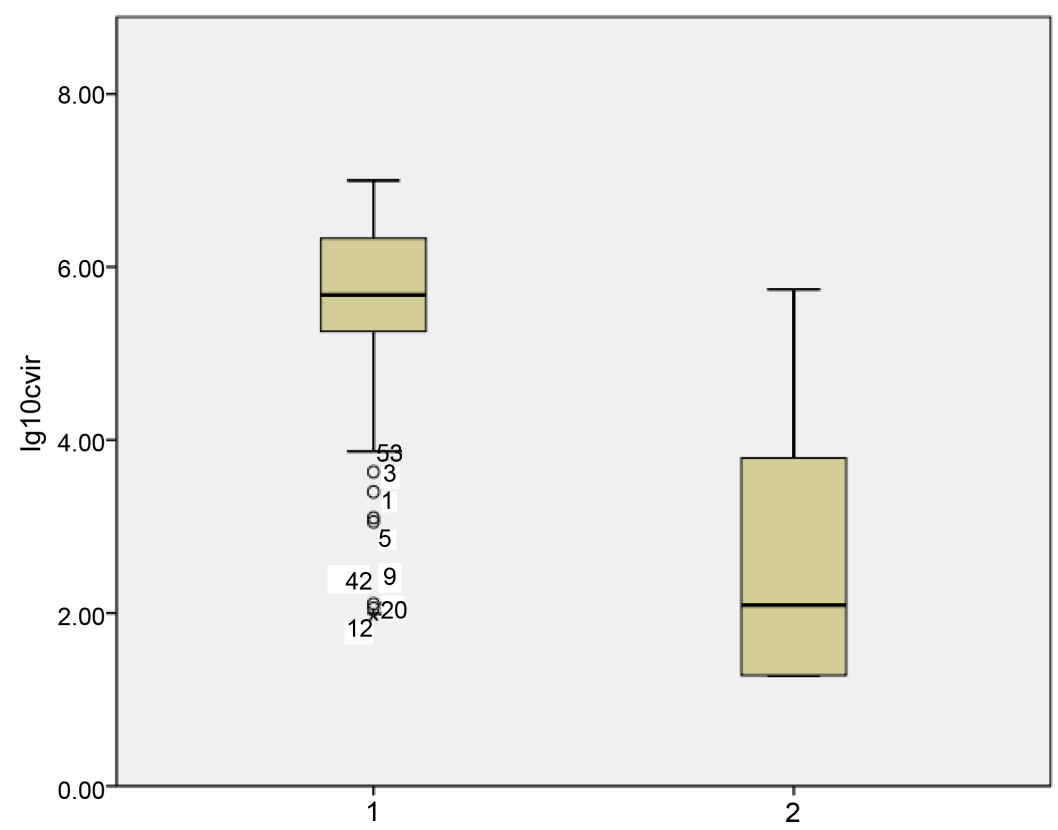

Graph 1. Distribution of viral load at the time of HIV diagnosis and at the time of the study. The scale is in logarithms of base 10, during the months of May to November of 2016, at the outpatient unit, pediatric infectiology of the Roosevelt Hospital. $n=56$. Source: Study Database [12] $1=$ Viral load at the time of diagnosis. $2=$ Viral load at the time of neurodevelopmental evaluation.

There was a significant decrease in viral load, $76.8 \%$ of patients had a viral load of 100,000 to 1,000,000 copies/ml at the time of HIV diagnosis, at the time of the study $<400$ copies/ml with an average of 60 months of TARGA.

The sample at the time of the evaluation was 26 patients. The rest of the patients (30) had undetectable viral loads of HIV, so they were not included in the graph.

Seventy-five percent of the patients studied were in stages B and $C$ and $39.2 \%$ of those in the immunological stage 3 , due to the late diagnosis of HIV in children in the country.

The choice of the current treatment, TARGA 1 and TARGA 2 of each patient was in agreement with the different mutations that they presented in their analysis.

\subsection{Neurodevelopment Indicators}

The sample was divided into two groups: 
All the patients evaluated had laboratory tests in their medical records and each was classified by their CD4 count and viral load, to establish in which stage they were (Table 2, Table 3).

Table 2. CD4 distribution at the time of HIV diagnosis and at the time of the study. May to November of 2016, at the outpatient unit, pediatric infectiology of the Roosevelt Hospital. $\mathrm{n}=56$ children.

\begin{tabular}{|c|c|c|}
\hline Characteristics & Cases & $\begin{array}{c}\text { Mean } \\
\text { (IC 95\%) }\end{array}$ \\
\hline Mean of CD4 at the time of diagnosis of HIV & & $\begin{array}{c}973 \\
(798,1149)\end{array}$ \\
\hline $\begin{array}{l}\text { Mean of CD4 at the time of neurodevelopmental } \\
\text { evaluation }\end{array}$ & & $\begin{array}{c}1164 \\
(1044,1284)\end{array}$ \\
\hline $\begin{array}{l}\text { Difference of CD4 between the time of } \\
\text { neurodevelopment assessment and the diagnosis of HIV }\end{array}$ & & $91.8(40,144)$ \\
\hline
\end{tabular}

Source: Study Database [12]. There was an increase in CD4 numbers with an average of 92 cells/ $\mu \mathrm{l}$, with a range of 40 to 144 cells/ $\mu$ l, with an average of 60 months of TARGA.

Table 3. Clinical and immunological characterization of children, during the months of May to November of 2016, at the outpatient unit, pediatric infectiology of the Roosevelt Hospital. $\mathrm{n}=56$.

\begin{tabular}{|c|c|c|c|c|c|}
\hline \multirow[t]{2}{*}{ Clinical Characteristics } & \multicolumn{5}{|c|}{ Cases } \\
\hline & & Stage "N" & Stage "A" & Stage "B" & Stage "C" \\
\hline & & $10(17.9 \%)$ & $4(7.1 \%)$ & $16(28.6 \%)$ & $26(46.4 \%)$ \\
\hline & 1 & $6(10.7 \%)$ & $3(5.4 \%)$ & $7(12.5 \%)$ & $8(14.3 \%)$ \\
\hline & 2 & $3(5.4 \%)$ & $1(1.8 \%)$ & $5(8.9 \%)$ & $0(0 \%)$ \\
\hline & 3 & $1(1.8 \%)$ & $0(0 \%)$ & $4(7.1 \%)$ & $18(32.1 \%)$ \\
\hline & \multicolumn{3}{|c|}{ Without treatment/ containment } & \multicolumn{2}{|c|}{$5(8.9 \%)$} \\
\hline \multirow[t]{3}{*}{ Treatment } & \multicolumn{3}{|c|}{ TARGA 1} & \multicolumn{2}{|c|}{$35(62.5 \%)$} \\
\hline & \multicolumn{3}{|c|}{ TARGA 2} & \multicolumn{2}{|c|}{$16(28.6 \%)$} \\
\hline & \multicolumn{3}{|c|}{ Without } & \multicolumn{2}{|c|}{$53(94.6 \%)$} \\
\hline Associated Pathology & \multicolumn{3}{|c|}{ With } & \multicolumn{2}{|c|}{$3(5.4 \%)$} \\
\hline
\end{tabular}

Source: Study Database [12] [14] [15] [16] [17] [18]. TARGA 1 = 2 Reverse Transcriptase Inhibitors nucleoside analogs +1 protease inhibitor TARGA $2=2$ Reverse transcriptase inhibitors nucleoside analogues + 1 Reverse transcriptase inhibitor NO nucleoside Containment Treatment $=$ Lamivudine (3TC).

-Bayley's scale. It was used in children under 3 years and 6 months of age. It consists of 5 tests that contain from 24 to 33 items which were evaluated depending on the age. The score was obtained by means of the right answers related to the standard scores for the patient's age (Graph 2) [12].

-McCarthy's scale: It was used in children from 3 years and 6 months of age to 8 years and 6 months of age. This scale consisted of 18 tests which were grouped into 6 skills; the tests were applied depending on the age of the patient. The score of each aptitude obtained through the evaluation was converted into a typical 
score by means of scales for the age of each patient; this score was used for this study (Graph 3) [12].

All children (100\% of the 6 children) scored at "risk" level in all skills assessed, which is why no estimates are presented for the different classification levels (Graph 2).

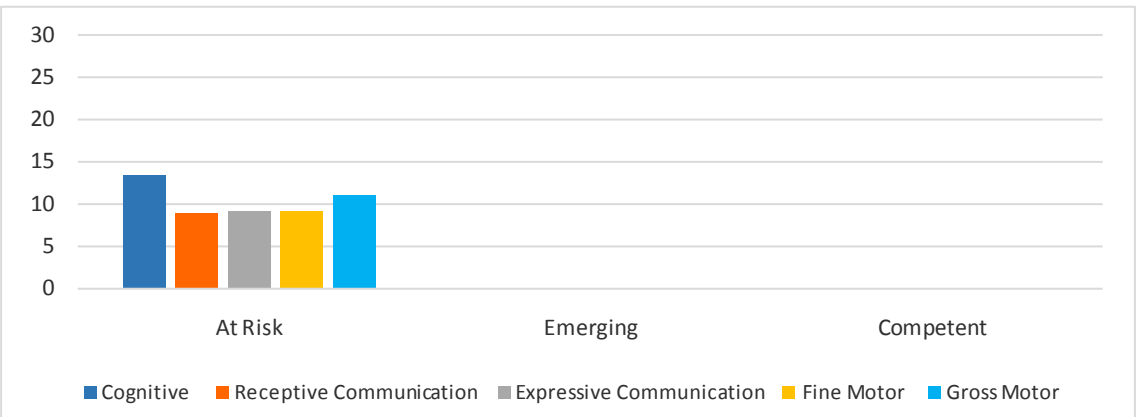

Graph 2. Scores obtained in the 5 areas of neurodevelopment through the Bayley scale, during the months of May to November of 2016, at the outpatient unit, pediatric infectiology of the Roosevelt Hospital. $\mathrm{n}=6$. Source: Study Database [12] [19].

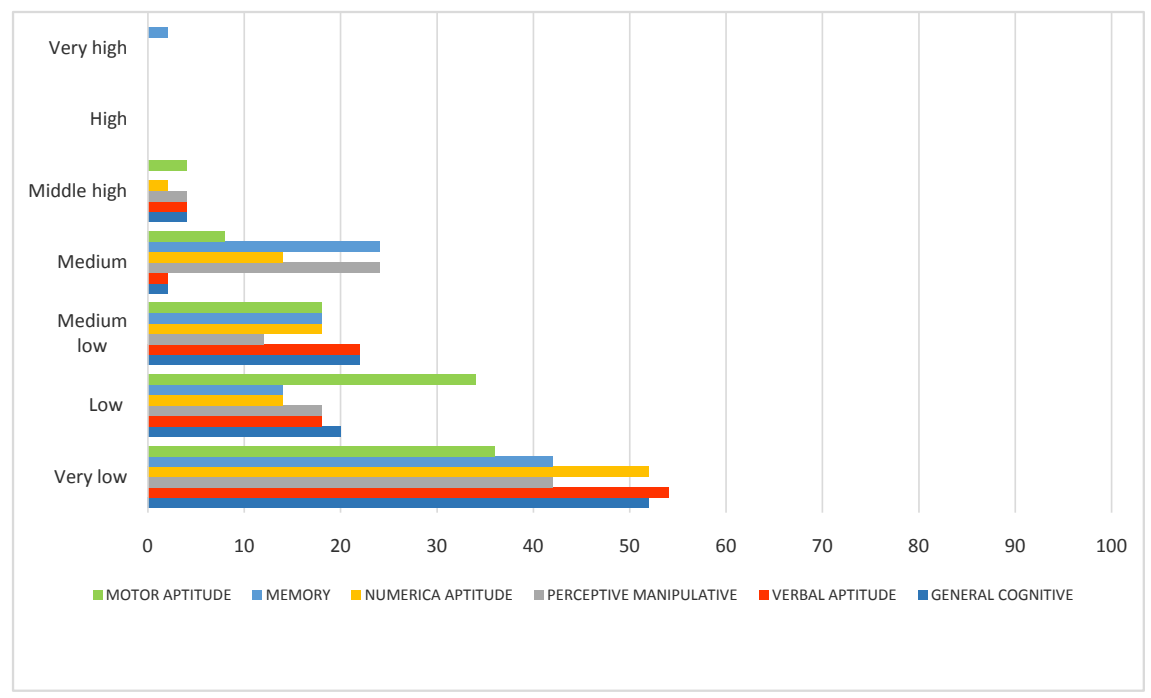

Graph 3. Percentage of children evaluated in the 6 areas of neurodevelopment using the McCarthy scale, during the months of May to November, 2016, at the outpatient unit, pediatric infectiology of the Roosevelt Hospital. $n=50$ Source: Study Database [12].

\section{Analysis and Discussion}

In 2015 , it was estimated that 4274 people aged 0 - 14 years were living with HIV. For the same year, 331 new cases that were considered mother-to-child transmissions were discovered. There is currently no new data indicating the exact number of pediatric patients living with HIV in the country [10] [20].

In Guatemala, there is no accurate information to determine the magnitude and distribution of cases of pediatric patients living with HIV [21]. In this type of patients, the diagnosis is often very difficult to perform, since there is no exact 
control of women with childbearing age infected with HIV in the country, with pregnancy in infected women being the main risk factor of children acquiring the infection by the vertical route, resulting in a late diagnosis [22] [23] [24].

The late diagnosis in these patients has been associated with multiple conditions and among them are alterations in neurological development. These alterations are due to the virus showing a rapid replication in the first years of life [13].

Multiple studies have shown that approximately $50 \%$ to $60 \%$ of infected pediatric patients present some neurological impairment in the early years, with an average age of 19 months to 3 years [20] [25] [26].

Data was obtained from 56 HIV-infected pediatric patients attending the outpatient unit, pediatric infectiology of the Roosevelt Hospital. The study included epidemiological, clinical and neurodevelopmental progressions.

Within the epidemiological characteristics obtained in the study it was found that:

- $91.1 \%$ of evaluated patients were female, which corresponded to $38.1 \%$ of the total population of children under 8 years and 6 months.

- As for the group according to age, no significant difference was found in the populations.

- Within the group according to schooling, it was found that $33.9 \%$ of the studied population did not have the school age (under 4 years) and that only $44.6 \%$ was attending some grade of nursery or elementary school, the rest of the evaluated population 21.4\%, were not attending school.

- According to the Ministry of Education, which is in charge of nursery, elementary and middle school education, the net enrollment rate by 2015 was $81 \%$ for the primary level, $19 \%$ of the population was not covered and approximately $4 \%$ belong to patients infected with HIV [27].

- According to birthplace of evaluated patients, it was found that $35.7 \%$ of the population is concentrated in the capital city; this may be due to the fact that in the western area of the country there is a care unit for patients infected with HIV since there is a poor diagnosis of HIV in the interior of the country.

- According to the child's caregiver type, it was found that $62.5 \%$ were in charge of the mother and $21.4 \%$ were in a shelter.

Among the clinical characteristics evaluated in the study it was found that:

- 35.7\% of the population had a diagnosis of HIV within the first 6 months of life; the result was equivalent to patients living in the capital city.

- $46.4 \%$ of patients infected with HIV were in stage C, indicating that their diagnosis was not early.

- Relating the two previous points, it is indicated that the patients diagnosed before 6 months of age, presented some disease that suggested the diagnosis of HIV, which confirms that there is not an adequate and correct diagnosis 
of the infection in pediatric patients.

- 91.1\% of the evaluated population were receiving antiretroviral treatment

[22] and $8.9 \%$ of the population were not. This was due to the group of patients who were in this treatment group (only with 1 medication, due to multiple resistances to the rest of antiretrovirals) or patients who were progressing slowly [28].

$100 \%$ of the patients under 3 years and 6 months of age were found to be at risk of neurodevelopmental alterations, according to Bayley's scale, probably due to lack of encouragement from the family member or caregiver.

Within the neurodevelopmental evaluation, it was found that between 36\% $54 \%$ of the evaluated patients from 3 years and 6 months to 8 years and 6 months of age, presented alterations in more than one area of neurodevelopment, with the McCarthy scale being correlated with studies carried out in other countries with $30 \%-70 \%$ of neurological involvement.

\section{Conclusions}

Between 36\% - 54\% of children aged 3 years and 6 months to 8 years and 6 months, had alterations in more than one area of neurodevelopment and $100 \%$ of children under 3 years and 6 months, were classified at risk level in all evaluated areas of neurodevelopment.

The most affected areas of neurodevelopment in children older than 3 years and 6 months to 8 years and 6 months were the verbal, numerical and cognitive areas, with very low scores for age, according to the McCarthy scale.

The clinical characteristics that were most related to neurodevelopment for children under 8 years and 6 months of age were, viral load and clinical stage, according to the Bayley and McCarthy neurodevelopmental scales.

The age at diagnosis is the most important epidemiological features associated with low and very low neurodevelopmental scores according to the McCarthy scale. There is an inversely proportional relationship between late diagnosis and neurodevelopment with low and very low scores for age.

\section{References}

[1] Puthanakit, T., Ananworanich, J., Vonthanak, S., Kosalaraksa, P., Hansudewechakul, R., et al. (2013) Cognitive Function and Neurodevelopmental Outcomes in HIV Infected Children Older Than 1 Year of Age Randomized to Early versus Deferred Antiretroviral Therapy: The PREDICT Neurodevelopmental Study, Cambolia and Thailand.

[2] Mancini, J. and Chabrol, B. (2010) Neurological Development. University Hospital Timone-Enfants, France.

[3] Velasco, M. and Losa, J. (2010) Neurological Manifestations of the Patient with HIV Infection. Hospital Universitario Fundación Alcorcón, Madrid.

[4] Álvarez, M., Alfonso, J. and Piñeiro, B. (2009) Neurologic Manifestations in AIDS Patients. Hospital Clinical-Surgical University. CMDTE. Faustino Peréz Hernández. Matanzas. 
[5] Bernal Cano, F. (2008) Human Immunodeficiency Virus HIV and Nervous System. General Principles, 18.

[6] Arribas, M., García, J.E., Núñez, L. and Gómez, R. (2009) Neurological Manifestations of the Patient with HIV Infection.

[7] Violari, A. (2007) Treating HIV-Infected Infants Early Helps Them Live Longer. South African Clinical Trial Modified Because of Initial Data, National Institutes of Health, Bethesda.

[8] González, F., Pérez, E., Ruiz, N., Acosta, P., Hernández, M., et al. (2007) Neurological Manifestations in Mexican Pediatric and Adolescent Patients Infected with HIV/AIDS. Experience in the Hospital Infantil the México Federico Gómez. Medigraphic [Online Journal].

[9] Astrulla, J., Cáceres, B. and Revilla, C. (2009) VIH: Vertical Transmission and Neurological Syndrome in Infants. Rev. Científica de Ciencia Médica v.12 n.2 Cochabamba.

[10] Ministry of Public Health and Social Assistance (2012) Estimates and Projections of HIV and Advanced HIV. National Center of Epidemiology, Guatemala.

[11] Muñoz, J.A. (2008) Neuro-SIDA en el niño.

[12] Palma, A. (2017) Neurodevelopment in Children under 8 Years and 6 Months with HIV, Roosevelt Hospital, Guatemala, June 2017. Undergraduate Thesis, University Rafael Landívar, Guatemala City.

[13] González Colorado, M.J. and Pocón Pocón, E.F. (2011) Risk Factors Associated with HIV Infection in Pediatrics: Case-Control Study in Children under 60 Months, Performed at Roosevelt Hospital, Department of Pediatrics and the Hospital for Rehabilitation and Infectious Childhood Diseases of Guatemala City during 2008-2010. Undergraduate Thesis, Universidad de San Carlos de Guatemala, Facultad de Ciencias Médicas.

[14] Pilar, K.M. (2004) Neurodevelopment in Young Children Exposed to HIV. UCES, Argentina.

[15] Rodríguez, S., Scrigni, A. and García, A.P. (2009) Highly Active Antiretroviral Therapy in HIV Seropositive Children. Disease Progression by Baseline Clinical, Immunological and Virological Status. Archivos Argentinos de Pediatria, v.107 n.3 Buenos Aires.

[16] Gonzalo, M.D. (2010) Neurological Complications Associated with HIV Infection.

[17] World Health Organization (2014) Antiretroviral Treatment in the Spotlight: A Public Health Analysis in Latin America and the Caribbean.

[18] Czornyj, L.A. (2006) Encephalopathy in Children Infected by Vertically Transmitted Human Inmunodeficiency Virus. Revista De Neurologia, 42, 743-753.

[19] Van Rie, A., Mupuala, A. and Dow, A. (2008) Impact of the HIV/AIDS Epidemic on the Neuro-Development of Preschool-Aged Children in Kinshasa, Democratic Republic of the Congo. Pediatrics, 122, e123-e128. https://doi.org/10.1542/peds.2007-2558

[20] Selik, R., Mokotoff, E., et al. (2014) Revised Surveillance Case Definition for HIV Infection-United States. Recommendations and Reports, 63, 1-10.

[21] Samayoa, B., Anderson, A., Grazioso, C., Rivera, B.E., Harrison, M., et al. (2009) Experience of a Pediatric HIV Clinic in Guatemala City. Revista Panamericana de Salud Pública, 25, 51-55. https://doi.org/10.1590/S1020-49892009000100008

[22] Laughton, B., Cornell, M., Boivin, M. and Van Rie, A. (2013) Neurodevelopment in Perinatally HIV-Infected Children: A Concern for Adolescence. Journal of the 
International AIDS Society, 16, 18603.

[23] OPS (2009) Definition of the WHO Case of HIV Infection for the Purpose of Surveillance and Review of Clinical Staging and Immunological Classification of the HIV-Related Disease in Adults and Children.

[24] Castillo, J.A. (2014) Infection Due to HIV/AIDS in the Current World. MediSan, 18, 117-138.

[25] Walker, S. and Pierre, R. (2013) Neurocognitive Function in HIV-Positive Children in a Developing Country. International Journal of Infectious Diseases, 17, e862-e867. https://doi.org/10.1016/j.ijid.2013.02.014

[26] ONUSIDA/OMS (2009) Joint United Nations Program on HIV/AIDS and the World Health Organization. Situation of the AIDS Epidemic.

[27] Ministry of Education, Guatemala (2013) National System of Educational Indicators.

[28] Organización Mundial de la Salud (2013) The Use of Antiretroviral Drugs for Treating and Preventig HIV Infection. 